\title{
Potassium Removal Increases the QTc Interval Dispersion during Hemodialysis
}

\author{
Adamasco Cupisti $^{a}$ Fabio Galetta ${ }^{a}$ Raffaele Caprioli ${ }^{b}$ Ester Morelli ${ }^{a}$ \\ Gian Carlo Tintori ${ }^{a}$ Ferdinando Franzoni ${ }^{a}$ Alberto Lippi ${ }^{b}$ Mario Meola ${ }^{a}$ \\ Paolo Rindi ${ }^{b}$ Giuliano Barsottia \\ a Dipartimento di Medicina Interna, Università di Pisa, and b Divisione Nefrologica, A.O. Pisana, Pisa, Italia
}

\section{Key Words}

QTc dispersion $\cdot$ Hemodialysis $\cdot$ Potassium

\begin{abstract}
This study was planned to clarify the mechanism(s) by which hemodialysis increases the QTc dispersion, a marker of risk of ventricular arrhythmias. To this aim, 10 uremic patients, without any relevant heart diseases, underwent two different types of hemodialysis schedules. In the first, $1 \mathrm{~h}$ of isolated high rate ultrafiltration preceded the standard diffusive procedure. In the second, during the first hour of standard bicarbonate hemodialysis, the decrease of plasma potassium concentration was prevented by increasing $\mathrm{K}^{+}$concentration in the dialysate, according to its pre dialysis plasma levels. During the high rate ultrafiltration period, together with ECG signs of increased sympathetic nervous system activity and catecholamines secretion, the QTc dispersion did not change significantly. Instead, an evident increment was observed $1 \mathrm{~h}$ after the start of the diffusive hemodialysis, then slowly progressing until the end of the dialysis and finally returning to the pre dialysis values within $2 \mathrm{~h}$ after the end of the session. To the contrary, the increase of the QTc dispersion was totally blunted during a standard hemodialysis procedure in absence of plasma $\mathrm{K}^{+}$decrease, but appeared again when the $\mathrm{K}^{+}$dialysate
\end{abstract}

\section{KARGER}

Fax +41613061234

E-Mail karger@karger.ch

www. karger.com
(C) 1999 S. Karger AG, Basel

$0028-2766 / 99 / 0822-0122 \$ 17.50$

Accessible online at:

http://BioMedNet.com/karger fluid concentration was restored to $2 \mathrm{mmol} / \mathrm{l}$. This study provides evidence that the increase of QTc dispersion occurring on hemodialysis is mainly related to the diffusive process, more precisely to the $\mathrm{K}^{+}$removal. This is one more reason to focus attention on $\mathrm{K}^{+}$removal rate especially when hemodialysis treatment is given in uremics affected by cardiac diseases with high risk of arrhythmias.

\section{Introduction}

The interlead variability of the QT interval in the surface electrocardiogram is called QT dispersion, defined as the difference between maximal and minimal QT interval duration. It reflects regional differences in ventricular recovery time [1].

Evidence exists that hemodialysis treatment causes an increased dispersion of QTc interval in a 12-lead electrocardiogram [2-4]. This suggests an increased regional heterogeneity of repolarization times in adjacent areas of the myocardium [5-7] and it is associated with higher risk of ventricular tachyarrhythmias in various conditions [811].

The changes of the intra- and extracellular electrolyte concentrations and of the autonomic nervous system or 
catecholamines secretion have been proposed to explain the well-known arrhythmogenic effect of the standard hemodialysis procedure [12, 13]. In particular, the sudden reduction of plasma potassium concentration as well as the elevation of ionized calcium plasma levels [14-16] can increase the susceptibility to ventricular arrhythmias. In fact, the intra- and extracellular concentrations of potassium, calcium and magnesium are important factors for the electrical stability of the myocardium, since they are involved in creating normal cellular excitability, impulse propagation and regular ventricular recovery. Of consequence, it is likely that the hemodialysis-induced electrolyte 'disequilibrium' could be the main cause of the increased QTc dispersion, but it has not been proven.

Moreover, other factors may potentially affect the QTc dispersion since the anatomic-functional heterogeneity among different areas of the ventricular myocardium can be developed by the several and complex modifications on the electrolytic status and on the autonomic nervous system balance occurring during the hemodialysis session. The present study was aimed to individually identify the factors responsible for the increased QTc dispersion following the hemodialysis procedure.

\section{Patients and Methods}

\section{Patients}

Ten chronic uremics ( 5 males and 5 females, aged $50 \pm 13$ years) on maintenance hemodialysis treatment entered the study.

Patients were maintained on thrice-weekly bicarbonate hemodialysis treatment lasting $4 \mathrm{~h}$. Polysulphone hollow fiber dialyzers (surface $1.8 \mathrm{~m}^{2}$ ) were used. The standard dialysate composition was the following: potassium $2 \mathrm{mmol} / \mathrm{l}$, calcium $1.75 \mathrm{mmol} / \mathrm{l}$, magnesium $0.37 \mathrm{mmol} / \mathrm{l}$, sodium $139 \mathrm{mmol} / \mathrm{l}$, chloride $109 \mathrm{mmol} / \mathrm{l}$, acetate 3 $\mathrm{mmol} / \mathrm{l}$ and bicarbonate $32 \mathrm{mmol} / \mathrm{l}$.

Patients affected by diabetes, heart failure, ischemic heart disease, atrial fibrillation or conduction disturbances were excluded as well as those with proven intra dialysis cardiovascular instability.

Two dimensional echocardiography examination was performed in all the studied patients: the detection of global or regional defects of contractility, or of an ejection fraction lower than $60 \%$, were regarded as exclusion criteria.

No patient was on pharmacological treatment known to affect the QTc interval. Informed consent from patients was obtained and the study was conducted in accordance with the principles of the Declaration of Helsinki.

\section{Study Design}

To separately evaluate the possible effects of the hemodialysisinduced changes of extracellular volume, of catecholamines, of autonomic nervous system activity and of electrolytes (namely potassium) on the QTc dispersion values, two different dialysis schedules were planned.
Study A. High rate isolated ultrafiltration was performed during the first hour of the session, then the ultrafiltration rate was reduced and a standard diffusive hemodialysis was begun and performed for $3 \mathrm{~h}$.

Surface 12-lead ECG recordings were taken before and after ultrafiltration, $1 \mathrm{~h}$ after the beginning of diffusive hemodialysis, at the end and $2 \mathrm{~h}$ after the end of the hemodialysis session. At the same times, arterial blood pressure was recorded and blood samples were taken from the afferent line for determinations of electrolytes, urea and creatinine plasma levels.

Seven days later, the same hemodialysis schedule was planned as above specified, and a 24-hour dynamic ECG monitoring was performed to assess the incidence of arrhythmias and the heart rate variability during and out of the hemodialysis session. Epinephrine and norepinephrine plasma levels were determined at baseline and at the end of the isolated ultrafiltration period.

Study B. During the first hour of a standard bicarbonate hemodialysis, the $\mathrm{K}^{+}$dialysate concentration was increased to obtain the same value of $\mathrm{K}^{+}$plasma level at the beginning of the session, then avoiding any plasma-dialysate $\mathrm{K}^{+}$gradient to prevent plasma $\mathrm{K}^{+}$levels from lowering. Then it was restored to a fixed concentration of $2 \mathrm{mmol} / \mathrm{l}$ for the following $3 \mathrm{~h}$ of hemodialysis.

Samples for plasma $\mathrm{K}^{+}$determinations and ECG recordings for evaluation of QTc dispersion were taken before and at the end of the hemodialysis period with high $\mathrm{K}^{+}$dialysate, then after $1 \mathrm{~h}$ and at the end of the following period of hemodialysis with low $\mathrm{K}^{+}$dialysate concentration.

\section{Methods}

The 12-lead electrocardiogram recordings were performed by Cardiovit CS-100 ECG Recorder (Schiller AG, Baar, Switzerland), at $50 \mathrm{~mm} / \mathrm{s}$ paper speed (gain $10 \mathrm{~mm} / \mathrm{mV}$ ).

The measurements of QT interval in all the possible leads were blindly performed by a single observer. The QT interval was taken from the onset of the QRS complex to the end of the T wave. In the presence of a $\mathrm{U}$ wave the nadir between $\mathrm{T}$ and $\mathrm{U}$ was taken as final point.

For each ECG recording we took measurements of three consecutive QT interval from each lead and calculated the arithmetic means; these QT values were then corrected (QTc) by the heart rate according to the Bazett's formula. The QTc dispersion was determined as the difference between the maximum and the minimum value of the QTc interval in different leads (ten at least) of the same ECG recording.

The arithmetic mean of the QTc from the 12 leads of each ECG recording was assumed as the QTc interval length.

Heart rate variability provides an index of cardiac sympatheticvagal balance: it was evaluated from $24 \mathrm{~h}$ continuous ECG recordings (Diagnostic Monitoring System USA), by measuring the standard deviation of all normal R-R intervals in the time domain (SDNN). The SDNN data during $2 \mathrm{~h}$ preceding the session and during the isolated ultrafiltration period were recorded.

The samples for plasma catecholamine assays were drawn by the afferent line, maintained on ice until refrigerated centrifugation was performed, then plasma was stored at $-70^{\circ} \mathrm{C}$ until assay was performed by the high-performance liquid chromatography method. The electrolytes and the other studied parameters were determined using the standard methods of our laboratory. 
Table 1. Study A: changes of the QTc dispersion and of the plasma concentrations of urea, creatinine and electrolytes, before and at the end of isolated ultrafiltration (UF), $1 \mathrm{~h}$ after, at the end and $2 \mathrm{~h}$ after the end of standard hemodialysis (HD)

\begin{tabular}{lccccc}
\hline & Before UF & End UF & $1 \mathrm{~h} \mathrm{HD}$ & End HD & After HD \\
\hline QTc dispersion, ms & $30 \pm 7$ & $34 \pm 5$ & $47 \pm 9^{\mathrm{b}}$ & $58 \pm 15^{\mathrm{a}}$ & $33 \pm 11$ \\
Urea, mg/dl & $132 \pm 38$ & $127 \pm 35$ & $72 \pm 20^{\mathrm{a}}$ & $47 \pm 15^{\mathrm{a}}$ & $63 \pm 21^{\mathrm{a}}$ \\
Creatinine, mg/dl & $10.3 \pm 1.78$ & $10.0 \pm 1.7$ & $6.6 \pm 2.0^{\mathrm{a}}$ & $4.3 \pm 1.0^{\mathrm{a}}$ & $5.6 \pm 1.1^{\mathrm{a}}$ \\
Sodium, mEq/l & $137 \pm 3$ & $136 \pm 4$ & $139 \pm 3$ & $139 \pm 4$ & $138 \pm 4$ \\
Potassium, mEq/l & $5.4 \pm 0.5$ & $5.6 \pm 0.9$ & $4.0 \pm 0.4^{\mathrm{a}}$ & $3.4 \pm 0.3^{\mathrm{a}}$ & $4.0 \pm 0.5^{\mathrm{a}}$ \\
Chloride, mEq/1 & $100 \pm 4$ & $99 \pm 5$ & $102 \pm 3$ & $102 \pm 4$ & $97 \pm 3$ \\
Calcium, mg/dl & $9.8 \pm 0.8$ & $10.5 \pm 1.1$ & $11.0 \pm 0.7^{\mathrm{b}}$ & $11.6 \pm 0.7^{\mathrm{a}}$ & $11.2 \pm 0.5^{\mathrm{b}}$ \\
Magnesium, mEq/l & $2.4 \pm 0.7$ & $2.5 \pm 0.7$ & $1.9 \pm 0.6$ & $1.7 \pm 0.5^{\mathrm{c}}$ & $2.0 \pm 0.6$ \\
Phosphorus, mg/dl & $4.9 \pm 1.9$ & $4.22 \pm 1.5$ & $2.5 \pm 0.9^{\mathrm{b}}$ & $2.2 \pm 0.7^{\mathrm{a}}$ & $3.6 \pm 1.2^{\mathrm{c}}$ \\
\hline
\end{tabular}

a $\mathrm{p}<0.001,{ }^{\mathrm{b}} \mathrm{p}<0.01,{ }^{\mathrm{c}} \mathrm{p}<0.05$ vs. before UF.

Table 2. Study A: mean QTc length, arterial blood pressure and heart rate values before and at the end of the isolated ultrafiltration period, $1 \mathrm{~h}$ after and at the end of the bicarbonate hemodialysis

\begin{tabular}{lcrrr}
\hline & Before UF & End UF & 1 h HD & End HD \\
\hline QTc length, ms & $416 \pm 13$ & $420 \pm 22$ & $430 \pm 21$ & $418 \pm 17$ \\
Systolic BP, mm Hg & $130 \pm 24$ & $122 \pm 20$ & $118 \pm 26$ & $129 \pm 33$ \\
Diastolic BP, mm Hg & $85 \pm 9$ & $81 \pm 13$ & $78 \pm 11$ & $84 \pm 16$ \\
Heart rate, bpm & $76 \pm 8$ & $74 \pm 11$ & $78 \pm 17$ & $86 \pm 15$ \\
\hline
\end{tabular}

\section{Statistical Analysis}

All the results are expressed as mean \pm SD. Statistical evaluation has been performed using the analysis of variance (ANOVA) for repeated measurements with the Bonferroni's multiple comparison test, and the Student's t test for paired data. 0.05 .

Differences were considered as statistically significant when $\mathrm{p}<$

\section{Results}

At the end of the hemodialysis session the QTc dispersion invariably increased but returned to the basal values within $2 \mathrm{~h}$ after the end of the hemodialysis (table 1). During the isolated high rate ultrafiltration $(1.3 \pm 0.6 \mathrm{~kg} / \mathrm{h})$ period the QTc dispersion did not change whereas a significant increase occurred already $1 \mathrm{~h}$ after the beginning of the hemodialysis procedure (table 1 ) with a low ultrafiltration rate $(0.4 \pm 0.2 \mathrm{~kg} / \mathrm{h})$. Then the QTc dispersion more slowly increased until the end of the session when the QTc dispersion reached the highest values, that was almost two times higher than at baseline. Finally, the QTc dispersion returned to the baseline values within $2 \mathrm{~h}$ after the end of the hemodialysis session (table 1).

The expected changes of the plasma biochemistry during the different phases of study $\mathrm{A}$ are shown in table 1. It emerges that the increment of QTc dispersion is associated with the decrease of potassium and magnesium and with the increase of calcium plasma levels.

Table 2 shows the values of the mean QTc length, arterial blood pressure and heart rate through the study A.

Norepinephrine circulating levels increased at the end of the high rate ultrafiltration period (fig. 1). Moreover, the SDNN values decreased during isolated ultrafiltration (fig. 1), reflecting a relative high sympathetic tone in this period.

However, study B clearly shows that the QTc dispersion does not change when a standard hemodialysis procedure is performed, provided that the potassium plasma concentration remains unchanged (fig. 2). Conversely, when potassium removal is restored, a rapid increase of 


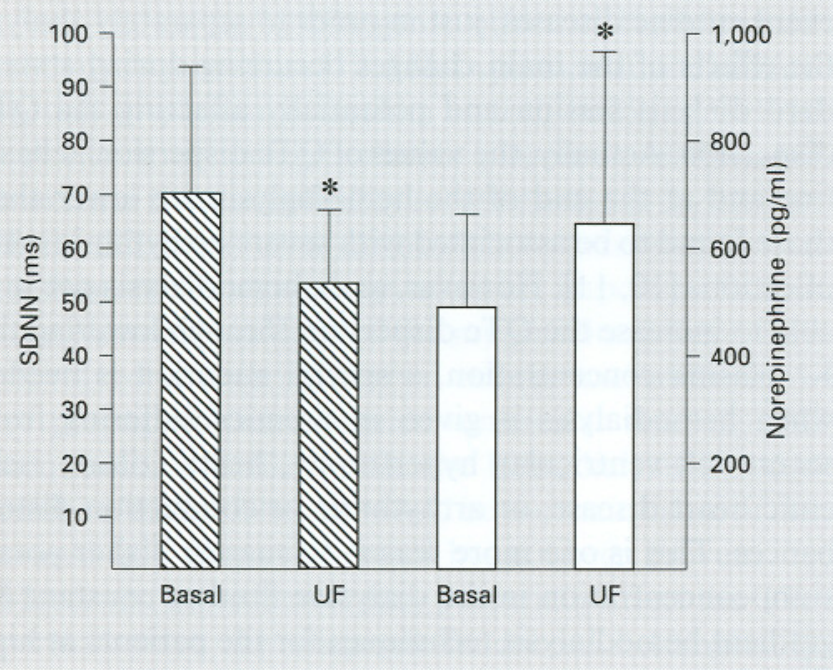

Fig. 1. Heart rate variability defined as the SD of all normal R-R intervals in the time domain (SDNN) values (dotted bars) and norepinephrine circulating levels (empty bars) before and during the isolated high rate ultrafiltration (UF) period (study A). Mean \pm SD. $* \mathrm{p}<0.05$ vs. basal value.

the QTc dispersion invariably occurred (fig. 2), similarly to that observed since the beginning of diffusive hemodialysis procedure in study A.

No clinically relevant arrhythmia was recorded by ECG Holter monitoring, neither during the time of the hemodialysis, nor during the time preceding or following it. In the studied patients, the incidence of ventricular or supra ventricular premature contractions was very low (as a mean, 1 and 10 per hour, respectively), and no significant abnormality related to the hemodialysis time period was observed.

\section{Discussion}

This study confirms that the standard bicarbonate hemodialysis procedure increases the QTc dispersion which seems to be independent of the technique used, since this effect was reported also when a soft hemodiafiltration, as it is the acetate-free biofiltration, was performed [4].

The increase of the QTc dispersion seems to be limited to the hemodialysis session, because it occurs from the first hour of dialysis, it is roughly two times greater at the end of the session, but it returns to basal values within $2 \mathrm{~h}$ after the end of the treatment.

QTc Dispersion and Potassium Removal

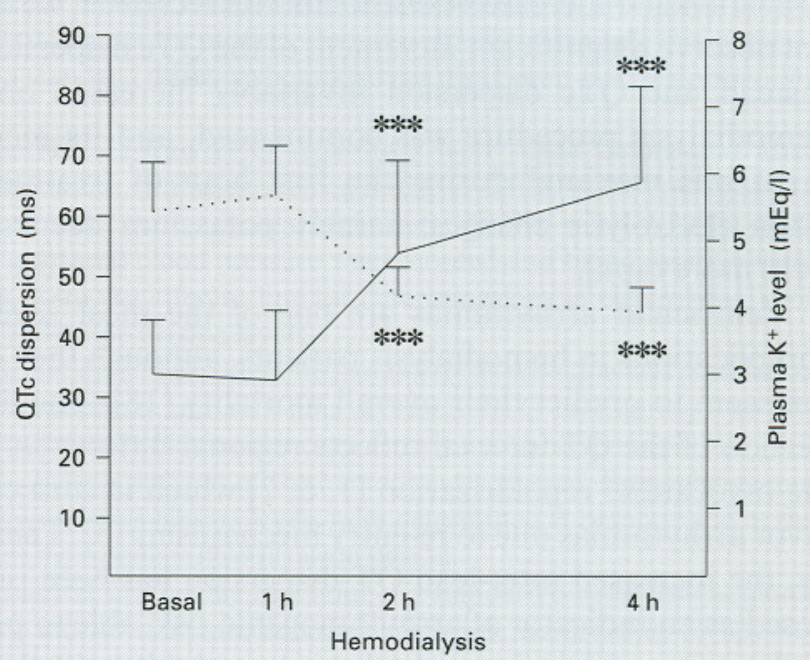

Fig. 2. Changes of the QTc dispersion values (solid line) and of the $\mathrm{K}^{+}$plasma levels (dotted line) in the patients given hemodialysis session with high $\mathrm{K}^{+}$dialysate concentration during the first hour, and with fixed low $\mathrm{K}^{+}$dialysate concentration during the following $3 \mathrm{~h}$ (study B). *** p $<0.001$ vs. basal and 1-hour values.

As far as the mechanism by which hemodialysis causes the increase of the QTc dispersion is concerned, the present study has focused the changes induced by the dialysis treatment on extracellular volume, autonomic nervous system activity, electrolytes and particularly on potassium extracellular concentrations.

Our results demonstrate that potassium removal is the critical factor inducing the enhancement of the QTc dispersion values during the hemodialysis session. This is in keeping with the authors claiming the role of potassium, and of its removal rate, as the main arrhythmias inducing factor associated with the hemodialysis treatment. Actually, Redaelli et al. [16] demonstrated that the arrhythmogenic effect of hemodialysis is blunted when a constant plasma-dialysate $\mathrm{K}^{+}$gradient is used instead of a fixed low $\mathrm{K}^{+}$dialysate concentration. In addition, low intracellular $\mathrm{K}^{+}$concentrations were found to be associated with an increased risk of ventricular arrhythmias [15].

The present study suggests a minor role of the autonomic nervous system and of the fluid volume changes in enhancing QTc dispersion during hemodialysis, in agreement with previous observations demonstrating no relation between QT dispersion and autonomic abnormalities in patients with left-ventricular hypertrophy and heart failure [17]. Indeed, during the isolated high rate ultrafiltration period, in the presence of strong sympathetic tone

Nephron 1999;82:122-126 
activation and increased catecholamines secretion, we did not observe a significant increment of the QTc dispersion. Instead, the QTc dispersion invariably increased once hemodialysis procedure was commenced, and its increment was maximal during the first hour of treatment when electrolytic changes, namely potassium decrease, were more rapid.

Ventricular arrhythmias are one of the most severe complications in hemodialysis patients, although they do not seem to predict their overall mortality [18]. The dispersion of the QT interval reflects regional differences of the myocardial repolarization $[1,6,7]$ which in turn can favor arrhythmias due to re-entry mechanisms [5]. Thereby, the increased inter-lead QT dispersion has been proposed as an indicator of arrhythmogenic risk, able to predict severe ventricular arrhythmias or sudden death in patients with hypertrophic cardiomyopathy [8, 9], myocardial infarction [10] or chronic heart failure [11].

Nevertheless, this study has failed to demonstrate a direct linkage between increased QTc dispersion and appearance of ventricular arrhythmias. It must be considered that this study was carried out in stable chronic ure- mics on maintenance hemodialysis, without clinically relevant cardiac diseases, just in order to separately analyze the effects of the main changes occurring during a standard dialysis session and potentially affecting the QTc dispersion. Actually, the values of QTc dispersion at baseline and at the end of the hemodialysis are lower than those found to be associated with severe arrhythmic complications [10,11]. However, since hemodialysis per se is able to increase the QTc dispersion through lowering the $\mathrm{K}^{+}$plasma concentration, a special attention is needed when hemodialysis is given in uremics suffering from severe left-ventricular hypertrophy, heart failure, ischemic heart disease, or arrhythmic or conduction disturbances. This is one more reason to suggest higher potassium concentration in the dialysate fluid or constant $\mathrm{K}^{+}$ gradient hemodialysis techniques for the patients at high risk of severe ventricular arrhythmias [16, 19].

In conclusion, the dispersion of the QTc interval does increase during hemodialysis by the lowering of the potassium plasma levels. Changes of the intradialysis potassium kinetics must be considered to reduce the risk of arrhythmias in hemodialysis patients.

\section{References}

1 Van de Loo A, Arendts W, Hohnloser SH: Variability of QT dispersion measurements in the surface electrocardiogram in patients with acute myocardial infarction and in normal subjects. Am J Cardiol 1994;74:1113-1118.

2 Cupisti A, Galetta F, Tintori GC, Sibilia G, Morelli E, Meola M, Barsotti G: Effetto del trattamento emodialitico sulla dispersione dell'intervallo QTc; in Timio M, Wizemann V, Venanzi S (eds): Cardionephrology 4. Cosenza, Bios Ed., 1997, pp 187-188.

3 Locati EH, Bagliani G, Saronio P, StrambaBadiale M, Timio M, Schwartz PJ: Increased QT interval dispersion following potassium decrease in nephropathic patients receiving hemodialysis; in Timio M, Wizemann V, Venanzi S (eds): Cardionephrology 4. Cosenza, Bios Ed., 1997, pp 173-177.

4 Cupisti A, Galetta F, Morelli E, Tintori GC, Sibilia G, Meola M, Barsotti G: Effect of hemodialysis on the dispersion of the QTc interval. Nephron 1998;78:429-432.

5 Burgess MJ: Relation of ventricular repolarization to electrocardiographic T-wave and arrhythmia vulnerability. Am J Physiol 1979;5: H391-H402.
6 Higham PD, Hilton CJ, Aitcheson DA, Furniss SS, Bourke JP, Campbell RWF: QT dispersion does reflect regional variation in ventricular recovery (abstract). Circulation 1992;86(suppl I):392.

7 Higham PD, Campbell RWF: QT dispersion. Br Heart J 1994;71:508-510.

8 Mayet J, Shahi M, McGrath K, Poulter NR, Sever PS, Foale RA, Thom SA: Left Ventricular Hypertrophy and QT dispersion in hypertension. Hypertension 1996;28:791-796.

9 Buja G, Miorelli M, Turrini P, Melacini P, Nava A: Comparison of QT dispersion in hypertrophic cardiomyopathy between patients with and without ventricular arrhythmias and sudden death. Am J Cardiol 1993;72:973-976.

10 Mirvis DM: Spatial variation of QT intervals in normal persons and patients with acute myocardial infarction. J Am Coll Cardiol 1985;5: 625-631.

11 Barr CS, Naas A, Freeman M, Lang CC, Struthers AD: QT dispersion and sudden unexpected death in chronic heart failure. Lancet 1994;343:327-329.

12 Gruppo Emodialisi e Patologie Cardiovascolari: Multicentre, cross-sectional study of ventricular arrhythmias in chronically hemodialysed patients. Lancet 1988;ii:305-309.

13 Abe S, Yoshizawa M, Nakanishi N, Yazawa T, Yokota K, Honda M, Sloman G: Electrocardiographic abnormalities in patients receiving hemodialysis. Am Heart J 1996;131:1137-1144.
14 Nishimura M, Nakanishi T, Yasui A, Tsuji Y, Kunishige $\mathrm{H}$, Hirabayashi M, Takahashi $\mathrm{H}$, Yoshimura M: Serum calcium increases the incidence of arrhythmias during acetate hemodialysis. Am J Kidney Dis 1992;19:149-155.

15 Rombolà G, Colussi G, De Ferrari ME, Frontini A, Minetti L: Cardiac arrhythmias and electrolyte changes during hemodialysis. Nephrol Dial Transplant 1992;7:318-322.

16 Redaelli B, Locatelli F, Limido D, Andrulli S, Signorini MG, Sforzini S, Bonoldi L, Vincenti A, Cerutti S, Orlandini G: Effect of a new model of hemodialysis potassium removal on the control of ventricular arrhythmias. Kidney Int 1996;50:609-617.

17 Davey PP, Bateman J, Mulligan IP, Forfar C, Barlow C, Hart G: QT interval dispersion in chronic heart failure and left ventricular hypertrophy: Relation to autonomic nervous system and Holter tape abnormalities. Br Heart J 1994; 71:268-273.

18 Sforzini S, Latini R, Mingardi G, Vincenti A, Redaelli B: Ventricular arrhythmias and fouryear mortality in hemodialysis patients. Lancet 1992;339:212-213.

19 Redaelli B: Electrolyte modelling in haemodialysis - potassium. Nephrol Dial Transplant 1996;11(suppl 2):39-41. 